\title{
Mutation in Spike Protein Cleavage Site and Pathogenesis of Feline Coronavirus
}

\author{
Beth N. Licitra, ${ }^{1}$ Jean K. Millet, ${ }^{1}$ Andrew D. Regan, Brian S. Hamilton, Vera D. Rinaldi, \\ Gerald E. Duhamel, and Gary R. Whittaker
}

Feline coronaviruses (FCoV) exist as 2 biotypes: feline enteric coronavirus (FECV) and feline infectious peritonitis virus (FIPV). FECV causes subclinical infections; FIPV causes feline infectious peritonitis (FIP), a systemic and fatal disease. It is thought that mutations in FECV enable infection of macrophages, causing FIP. However, the molecular basis for this biotype switch is unknown. We examined a furin cleavage site in the region between receptor-binding (S1) and fusion (S2) domains of the spike of serotype 1 FCoV. FECV sequences were compared with FIPV sequences. All FECVs had a conserved furin cleavage motif. For FIPV, there was a correlation with the disease and $\geq 1$ substitution in the S1/S2 motif. Fluorogenic peptide assays confirmed that the substitutions modulate furin cleavage. We document a functionally relevant $\mathrm{S} 1 / \mathrm{S} 2$ mutation that arises when FIP develops in a cat. These insights into FIP pathogenesis may be useful in development of diagnostic, prevention, and treatment measures against coronaviruses.

$\mathrm{F}$ eline infectious peritonitis (FIP) is a fatal infection that affects domestic and wild members of the family $\mathrm{Fe}$ lidae and is caused by a feline coronavirus $(\mathrm{FCoV})$ of the family Coronaviridae, subfamily Coronavirinae, genus Alphacoronavirus, species Alphacoronavirus-1 (1). The $\mathrm{FCoV}$ genome is $\approx 29 \mathrm{kB}$ and has 11 open reading frames encoding replicative, structural, and accessory proteins (2). Two serotypes have been identified. Serotype 1 FCoVs are highly prevalent clinically (3-5) but grow poorly in cell culture and are therefore underevaluated when compared with serotype $2 \mathrm{FCoVs}$, which are easily propagated in vitro but less prevalent.

Within each serotype, there are 2 biotypes, each causing distinct disease outcomes. Feline enteric coronavirus

Author affiliation: Cornell University College of Veterinary Medicine, Ithaca, New York, USA

DOI: http://dx.doi.org/10.3201/eid1907.121094
(FECV) of serotypes 1 and 2 infects enterocytes, causing mild and generally self-limiting infections. FECV spreads efficiently through the oral-fecal route, and chronically infected cats can shed infectious virus in feces for a year or longer $(6,7)$. The second biotype found in both serotypes, FIP virus (FIPV) is found less frequently but causes FIP.

The current understanding is that FIPV arises during in vivo infection from a genetic mutation of FECV (8-11). A long-standing hypothesis is that FIP viruses arise from internal mutation of endemic FECVs (12), which is believed to occur in approximately $1 \%-5 \%$ of enteric infections, resulting in the ability of the virus to infect blood monocytes and tissue macrophages. The resulting productive infection of these cells, a hallmark of FIP, enables systemic spread and results in macrophage activation, with concomitant immune-mediated events leading to death. To date, the precise mutation or mutations that cause a shift in $\mathrm{FCoV}$ biotype have not been identified.

As with other RNA viruses, coronavirus replication is error-prone; the estimated mutation rate is $\approx 4 \times 10^{-4}$ nucleotide substitutions/site/year $(13,14)$. It has been suggested that mutations in the $3 \mathrm{c}$ and $7 \mathrm{~b}$ genes may be involved in the transition to FIPV $(1,12,15)$. Because FCoV spike protein plays critical roles in receptor binding (S1) and fusion (S2), we focused on structural changes in this protein and potential role in altered cellular tropism. In particular, acquisition of macrophage tropism for a serotype $2 \mathrm{FCoV}$ has previously been mapped to the spike gene (16), further suggesting that key mutations within spike protein may be important for the biotype switch.

The coronavirus spike protein is a class I fusion protein, which typically requires activation by cellular proteases. Mutation of the proteolytic cleavage site often has profound implications for disease progression $(17,18)$. Until recently, FCoVs were thought to have uncleaved spike

${ }^{1}$ These authors contributed equally to this article. 
protein. However, a functional furin cleavage site has been identified in 2 serotype 1 FECVs, located at the shared boundary of the $\mathrm{S} 1$ and $\mathrm{S} 2$ subunits (19). Furin is a ubiquitous proprotein convertase enriched in the trans-Golgi network and is well-conserved among mammals (20). Furin cleaves a wide range of protein precursors into biologically active products at a consensus motif $\mathrm{R}-\mathrm{X}-\mathrm{K} / \mathrm{R}-\mathrm{R}$, where $\mathrm{R}$ is the basic arginine residue, $\mathrm{X}$ is any residue, and $\mathrm{K}$ is the basic lysine residue (21).

In this article, we establish a novel approach to studying FIP that complements previous work. Instead of performing a mutation study based mainly on comparative genetic analysis $(15,22-24)$, we focus on S1/S2, a functionally relevant site, and study variations between the biotypes and their functional effects. This rationale could provide a better means to uncover functionally important mutations that account for FIP.

We considered that mutations at the $\mathrm{S} 1 / \mathrm{S} 2$ site could alter proteolytic cleavage and modify $\mathrm{S}$ fusogenic properties, leading to tropism expansion, systemic spread and, ultimately, FIP. We investigated genetic variations at the S1/ S2 site of serotype 1 FECVs and compared these sequences to those present in viral RNA recovered from tissues of cats with FIP. Fluorogenic peptide cleavage assays were conducted to assess the effects of substitutions found in the $\mathrm{S} 1 / \mathrm{S} 2$ site. We document a junction mutation at $\mathrm{S} 1 / \mathrm{S} 2$ that arises during development of FIP. Our study has uncovered a molecular basis for FIP that has potential to lead to developments in diagnostics, prevention, and therapies.

\section{Materials and Methods}

\section{FCoV Sequence Analysis}

Clinical and demographic data are reported in online Technical Appendix Table 1 (wwwnc.cdc.gov/EID/ article/19/7/12-1094-Techapp1.pdf). Fecal samples from asymptomatic infected domestic cats were solicited from shelters and veterinarians throughout the United States. RNA was extracted by using QIAamp Viral RNA Mini Kit (QIAGEN, Valencia, CA, USA). FCoV primers that detect most circulating strains were used to screen all fecal samples (25). RNA extracted from FIPV-TN406 (Black) laboratory-adapted strain was used as a positive control.

We analyzed 22 FIPV-positive tissue samples (Veterinary Pathology Archives, Cornell University, Ithacan, NY, USA) from 11 cats with FIP. Diagnosis of FIP was based on the standard method of immunohistochemical evaluation by board-certified pathologists. Each sample was retrieved from formalin-fixed, paraffin-embedded tissue blocks from which sections were stained by using FIPV 3-70 antibody (Custom Monoclonals, Sacramento, CA, USA). Positively stained regions were thinly sectioned and RNA was extracted by using RecoverAll (Ambion, Foster City, CA, USA).
Fecal samples collected from FCoV-positive housemates, cats 234 and 304, were processed as previously described in this section. After the referring veterinarian made a diagnosis of FIP in cat 234, the owner elected to euthanize the animal. Fresh tissue was harvested and RNA extracted by using MagMAX Express (Life Technologies, Grand Island, NY, USA).

For all samples, $50 \mu \mathrm{L}$ reverse transcription PCRs (RTPCRs) were performed with One-Step RT-PCR (QIAGEN) by using gene-specific $\mathrm{S}$ primers, encompassing S1/S2. The PCR primers sequences are found in online Technical Appendix Table 2. PCR conditions were $30 \mathrm{~min}$ at $50^{\circ} \mathrm{C}, 15$ min at $95^{\circ} \mathrm{C}$, and 39 or 35 cycles of 1 min at $94^{\circ} \mathrm{C}, 1 \mathrm{~min}$ at $55^{\circ} \mathrm{C}, 1$ or $1.5 \mathrm{~min}$ at $72^{\circ} \mathrm{C}$, and $10 \mathrm{~min}$ at $72^{\circ} \mathrm{C}$. PCR products were purified by using a QIAquick Gel Extraction Kit (QIAGEN). Sanger sequencing was performed at the Life Sciences Core Laboratories (Cornell University). Nucleotide archive accession numbers are shown in online Technical Appendix Table 4. DNA sequences were translated into protein sequences and alignments were performed by using Geneious 5.4 (Biomatters Ltd., Auckland, New Zealand). Sequence logos were generated by using Weblogo 3.1 (http://weblogo.threeplusone.com/). Statistical analysis was performed by using 2-tailed Fischer exact test. In the test, the numbers of FIPV-infected and FECV-infected cats were counted. For each category of FIPV or FECV infection, cats harboring viruses with or without mutations at the $\mathrm{S} 1 / \mathrm{S} 2$ site were counted.

\section{Furin Cleavage Assay}

Fluorogenic 12-mer peptides were designed and synthesized by RS Synthesis, Louisville, KS, USA (online Technical Appendix Table 3). Purified recombinant human furin was purchased from NEB (Ipswich, MA, USA). For each reaction, 1 unit of enzyme was used in $100 \mu \mathrm{L}$ final volume by using the reaction buffer $100 \mathrm{nmol} / \mathrm{L}$ HEPES, $0.5 \%$ Triton $\mathrm{X}-100,1 \mathrm{mmol} / \mathrm{L} \mathrm{CaCl}_{2}, 1 \mathrm{mmol} / \mathrm{L}$ 2-mercaptoethanol, $\mathrm{pH}$ 7.5. Peptides were diluted to $50 \mu \mathrm{mmol} / \mathrm{L}$. Reactions were performed in triplicate at $30^{\circ} \mathrm{C}$ and fluorescence was measured with a SpectraMax fluorometer (Molecular Devices, Sunnyvale, CA, USA), enabling Vmax determination. Results for each peptide are expressed as percent cleavage by furin compared with the canonical sequence.

To perform comparative analysis of the $\mathrm{S} 1 / \mathrm{S} 2$ cleavage site between FECVs and FIPVs, we identified cases of FIP that were confirmed postmortem by using immunohistochemistry, the standard for FIP diagnosis; archival immunohistochemistry-positive formalin-fixed tissues were used as the source of FIPV RNA. To ensure good quality sequence information from archival material, the RT-PCR amplicon size was limited to $160 \mathrm{bp}$ (including the $\mathrm{S} 1 / \mathrm{S} 2$ site). This same region was then amplified from fecal material from coronavirus-positive healthy cats. 


\section{Results}

\section{FECV S1/S2}

Sequencing of the $\mathrm{S} 1 / \mathrm{S} 2$ site of $30 \mathrm{~S}$ sequences from FECV fecal samples revealed an extremely well-conserved motif at the amino acid level (Figure 1, panel A). In particular, arginine $(\mathrm{R})$ residues are found exclusively at the most critical positions for furin recognition and cleavage $(\mathrm{P} 1, \mathrm{P} 2$, and $\mathrm{P} 4)$ in all sequences analyzed (Figure 2, panel B). The P1' position is extremely well conserved, because serine (S) is found in $100 \%$ of cases. The P5 position is also well conserved, evidenced by a clear majority of basic residues found $(96.6 \%$ arginine or lysine [K]; Figure 2, panel B). At P3, limited variability is found $(76.7 \%$ serine and $23.3 \%$ alanine $[\mathrm{A}]$ ). Overall, $100 \%$ of FECV sequences analyzed contain the furin cleavage site, with a core motif of R-R-S/A-R-R-S.

\section{FIPV S1/S2}

Analysis of the S1/S2 cleavage site of FIPV sequences shows that it has much more variability, both within the narrow furin cleavage recognition motif (P4-P1) and in residues extending out of it (P8-P5 and P2'-P4') (Figure 2A). A striking observation is that the critical positions $\mathrm{P} 1$ and $\mathrm{P} 2$ are among the most consistently mutated (Figure 3 ). To a lesser degree, variability extends to other positions of the cleavage motif, notably in the $\mathrm{P} 1{ }^{\prime}, \mathrm{P} 3, \mathrm{P} 4$, and $\mathrm{P} 5$ positions (Figure 2). Examination results of the entire portion of spike sequenced in this study indicate that the conserved R-R-S/A-R-R-S motif in FECV is present within a region of the spike gene that shows a high degree of variability, in contrast to other neighboring regions that are more highly conserved (online Technical Appendix Figure 1).

\section{Correlation between FIP Status of Cats and Presence of Mutations at S1/S2}

A Fisher exact test was performed to establish whether a correlation existed between the FIP status of the sampled cats and mutations at the S1/S2 site of viruses analyzed (Table 1). The test unequivocally demonstrated that there was a strong correlation $(p<0.0001)$ between FIP and presence of mutations at $\mathrm{S} 1 / \mathrm{S} 2$.

\section{Fluorogenic Peptide Furin Cleavage Assay}

To test whether the identified FIPV S1/S2 mutations have an effect on cleavability by furin, we performed an in vitro proteolytic assay. We used human furin for these experiments. Human and feline furin are very similar $(96 \%$ identical) and are expected to cleave in an equivalent manner. However, feline furin has not been directly studied to any degree, and reagents are not readily available. Feline and human cells lines show identical rates of cleavage for a known furin target protein (PSCK-9), which contains an active furin

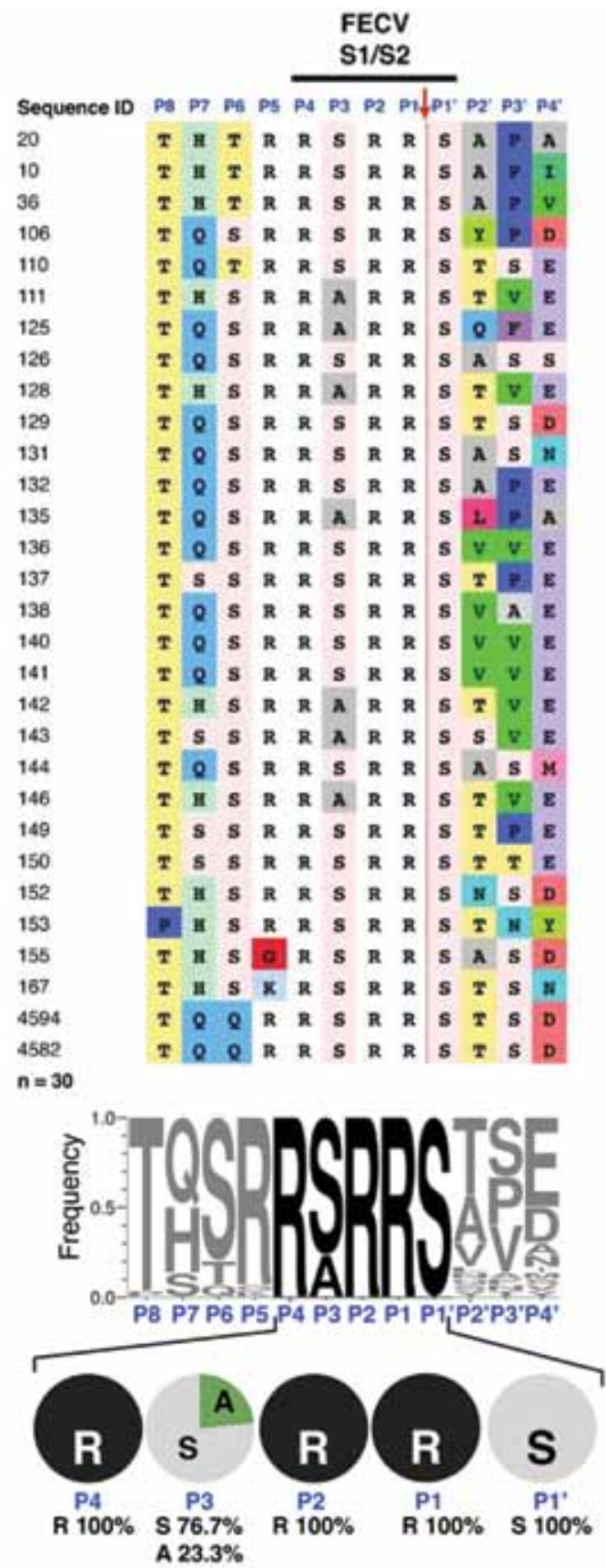

Figure 1. Sequence analysis of feline enteric coronavirus (FECV) spike S1/S2 site. RNA from 30 FECVs collected from 30 fecal samples obtained from subclinically infected cats was extracted, purified, and reverse-transcribed into cDNA. Sequencing of the spike gene was performed in a region surrounding the $\$ 1 / S 2$ cleavage site. A) Sequence alignment. Sequence identification row (blue font): residue positions in the S1/S2 cleavage site from P8 to $\mathrm{P} 4{ }^{\prime}$. Red arrow indicates the site of furin cleavage. B) To visualize the diversity of residues at each position of the S1/S2 site, sequences were subjected to WebLogo 3.1 analysis (http://weblogo.threeplusone. com/create.cgi). Top: WebLogo for the $30 \mathrm{FECV} \mathrm{S1/S2} \mathrm{sequences}$ with the frequency of residue found at each position displayed. Bottom: summary of the diversity of residues for each position from P4 to P1' and percentages of each amino acid represented. 


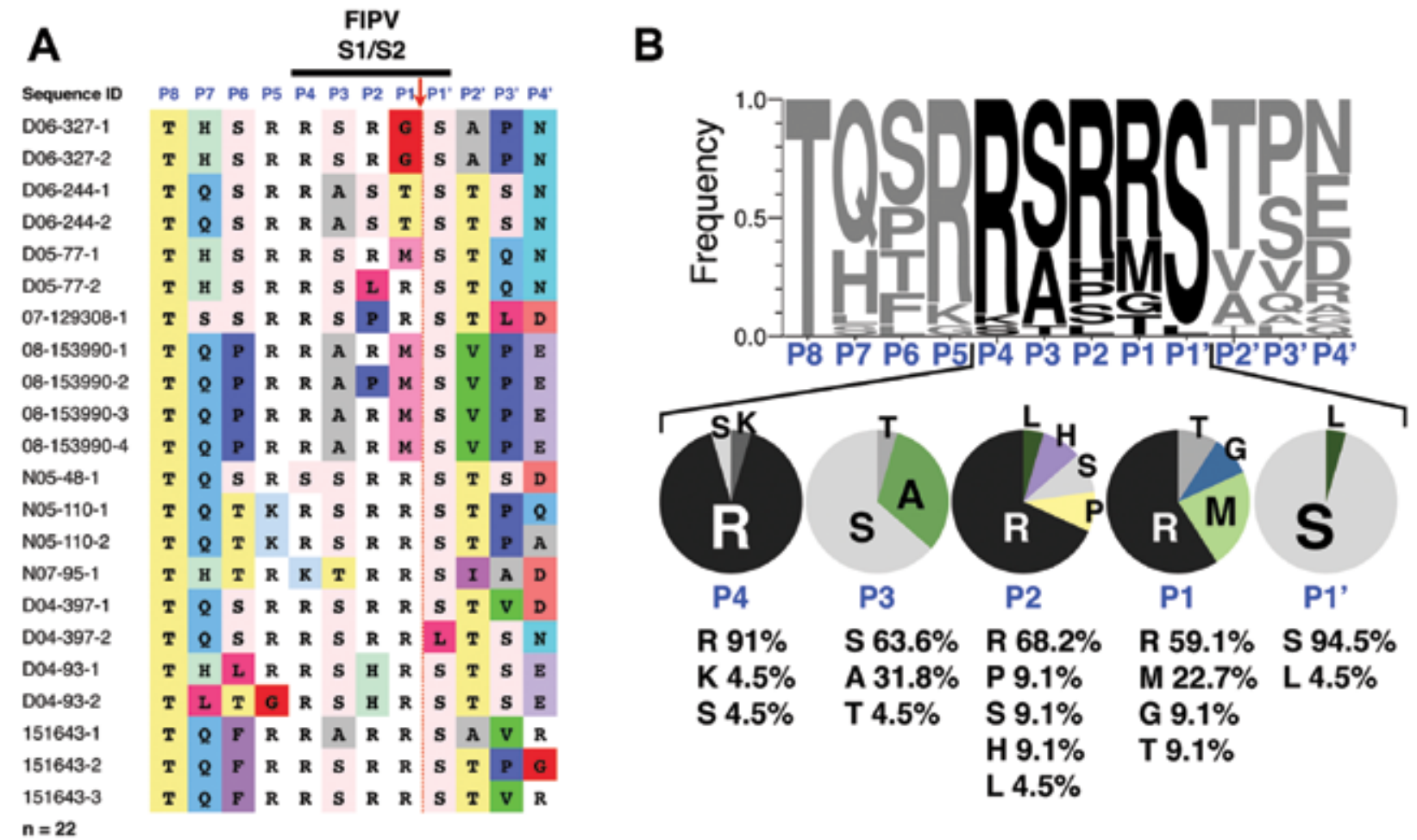

Figure 2. Sequence analysis of feline infectious peritonitis virus (FIPV) spike S1/S2 site. RNA from 22 FIPVs collected from 11 cats who had feline infectious peritonitis was extracted, purified, and reverse-transcribed into cDNA. Sequencing of the spike gene was performed in a region surrounding the S1/S2 cleavage site. A) Sequence alignment. Sequence identification row (blue font): residue positions in the S1/S2 cleavage site from P8 to P4'. Red arrow indicates the site of furin cleavage. B) To visualize the diversity of residues at each position of the S1/S2 site, sequences were subjected to WebLogo 3.1 analysis (http://weblogo.threeplusone.com/create.cgi). Top: WebLogo for the 22 FIPV S1/S2 sequences with the frequency of residue found at each position displayed. Bottom: summary of the diversity of residues for each position from P4 to P1' and percentages of each amino acid represented.

cleavage site (online Technical Appendix Figure 2). We used fluorogenic peptides containing the canonical motif (RR-S-R-R-S) or with substitutions from positions P1' through P7 (Figure 4, panel A). The canonical peptide was efficiently cleaved by furin (Figure 4), with average Vmax of 235 Relative Fluorescence Units (RFU) per minute.

Within the P4-P1' core peptide, in the canonical background, when the $\mathrm{P} 1$ ' serine residue is changed into a leucine $(\mathrm{L})$, furin cleavage is severely diminished ( $8 \%$ of canonical cleavage rate), a result that shows the key role of the conserved $\mathrm{P} 1$ ' serine. Modifications of the $\mathrm{P} 1$ arginine in the canonical peptide, regardless of the residue tested, for example, glycine $(\mathrm{G})$, methionine $(\mathrm{M})$ or threonine (T), abrogate cleavage by furin (Figure 4). Modifications at the $\mathrm{P} 2$ arginine residue in the canonical peptide have variable effects. When $\mathrm{P} 2$ arginine is changed to histidine $(\mathrm{H})$, there is complete inhibition $(0 \%$ of canonical cleavage). When $\mathrm{P} 2$ is changed to leucine or serine, cleavage efficiency is reduced by $\approx 50 \%$ and $20 \%$, respectively. When $\mathrm{P} 2$ is modified to proline $(\mathrm{P})$, cleavage efficiency slightly increases to $129 \%$ of the canonical peptide (Figure 4). The P3 S-A substitution minimally enhances cleavage
(Figure 4). P4 arginine is another residue position that is essential for furin cleavage. In the canonical peptide, P4 $\mathrm{R}-\mathrm{K}$ substitution, there is a slight decrease in cleavage efficiency ( $88.7 \%$ of canonical rate). In contrast, when the P4 arginine is substituted with glycine, furin cleavage is completely abrogated (Figure 4).

For positions upstream of P4, while P5 R-K and P6 T-F modifications have moderate enhancing effects on furin cleavage (149\% and $162 \%$ of canonical rate, respectively), the P7 H-Q peptide shows a substantial increase in its cleavability (186\% compared with canonical). The P7 H-Q P5 R-K peptide shows that the effect of each modification can be additive (232\% compared with canonical peptide) (Figure 4).

\section{Functionally Relevant S1/S2 Mutation}

To further confirm our findings, we analyzed the S1/ S2 sites from viral samples taken from cats 234 and 304, who lived in the same household (Table 2). At the initial sampling in $2009(\mathrm{t}=1)$, both cats were asymptomatic for FIP and were shedding FCoV in their feces. In samples from both cats, the S1/S2 sites had a core sequence 


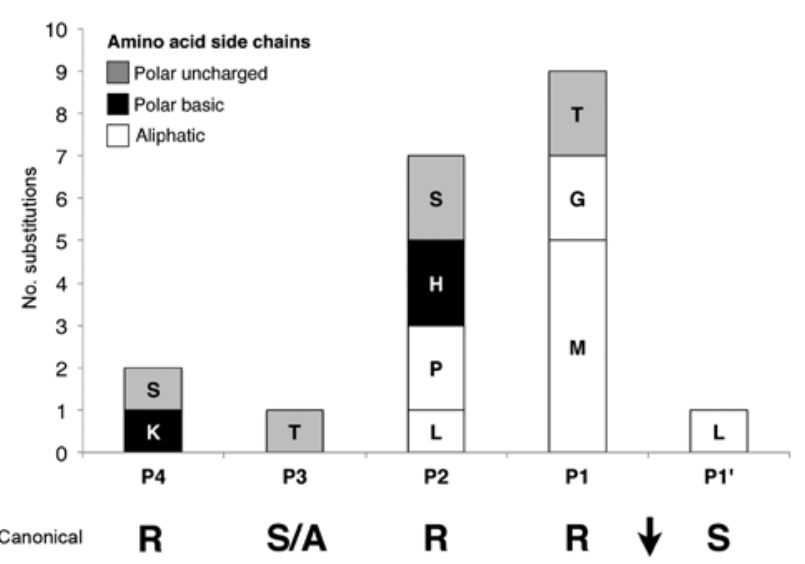

Figure 3. Amino acid substitution frequency at each position of the feline infectious peritonitis virus S1/S2 cleavage site. The histogram is based on feline infectious peritonitis virus S1/S2 WebLogo 3.1 analysis (http://weblogo.threeplusone.com/create.cgi), showing percentage of modification of residues at each position of the S1/ $\mathrm{S} 2$ site, compared with feline enteric coronavirus S1/S2 canonical sequence consensus.

R-R-S-R-R-S consistent with the FECV consensus. Upon the second sampling in 2011/2012 ( $\mathrm{t}=2)$, FIP was diagnosed in cat 234. Cat 304 remained asymptomatic but continued to shed virus in feces. Notably, when the S1/ S2 sequences were analyzed at the second sampling, only the cat with FIP (234) had a change in the FECV consensus sequence (a P2 R-L mutation). While exhibiting a change in the $\mathrm{P} 3$ residue ( $\mathrm{S}-\mathrm{A})$, the virus present in cat 304 retained the conserved S1/S2 furin cleavage motif (Table 2). These data provide direct evidence of mutations in spike linked with development of FIP in cats.

\section{Discussion}

To study FIP, we have taken an alternative approach that complements earlier studies that were based on analytical outcomes of putative FIP-causing mutations and inference of their functional consequences. We focused on the $\mathrm{S} 1 / \mathrm{S} 2$ sequence, a specific and functionally highly relevant cleavage site within the $\mathrm{S}$ protein, and documented mutations between asymptomatic and highly symptomatic cats that correlated strongly with FIP. We also documented a functional S1/S2 cleavage site mutation that arose in an asymptomatic cat that subsequently developed FIP.

Our sequence data show that serotype 1 FECV from feces of asymptomatic cats contain a highly conserved furin cleavage motif at the $\mathrm{S} 1 / \mathrm{S} 2$ site, with the following narrow range of residues: $(\mathrm{R}>>\mathrm{K} / \mathrm{G})^{\mathrm{P} 5}-(\mathrm{R})^{\mathrm{P} 4}-(\mathrm{S}>\mathrm{A})^{\mathrm{P} 3}-(\mathrm{R})^{\mathrm{P} 2}-$ $(\mathrm{R})^{\mathrm{P} 1}-(\mathrm{S})^{\mathrm{P} 1}$. In addition to the consensus $\mathrm{R}-\mathrm{X}-\mathrm{K} / \mathrm{R}-\mathrm{R}$ motif, additional flanking residues can also be consequential for furin-mediated cleavage (26-28). In particular, a serine (S) residue is critical in the $\mathrm{P} 1^{\prime}$ position (29) and it is notable that all FECVs examined contained a $\mathrm{P} 1^{\prime} \mathrm{S}$ residue. The fact that the $\mathrm{S} 1 / \mathrm{S} 2$ site is extremely well conserved is an indication that it is functionally essential for FECV replication in the enteric epithelium.

In contrast to the situation for asymptomatic cats infected with FECV, we found that sequences of FCoV sampled from tissue of confirmed FIP-positive cats consistently have mutations at the $\mathrm{S} 1 / \mathrm{S} 2$ site. In the most critical position for furin cleavage, P1, we found that $>40 \%$ of FIPVs have a mutation in the arginine residue, which is replaced by an aliphatic (methionine and glycine) or polar uncharged (threonine) residue. Overall, the distinguishing feature of FIPVs is the absence of the P1 arginine, rather that the presence of any particular residue. This is corroborated by our peptide cleavage data that demonstrate that furin cleavage is fully abrogated for all P1 substitutions tested. The next most common position mutated in FIPV is $\mathrm{P} 2 ;>30 \%$ of the FIPVs analyzed bore mutations at this position. Most mutated residues found were aliphatic ( $\mathrm{P}$ and L). Some sequences were substituted with a polar basic $(\mathrm{H})$ or a polar uncharged (S) residue. Apart from the P2 R-P substitution, peptide cleavage data indicates that all other substitutions have an inhibiting effect on furin cleavage. Of note, for murine hepatitis virus (MHV), a betacoronavirus that also harbors an S1/S2 cleavage site in its spike protein, there is a precedent for the inhibitory effect of the introduction of a histidine in the $\mathrm{P} 2$ position of the cleavage site. Two well-studied strains, MHV strain A59 (MHV-A59) and the neurovirulent MHV strain JHM (MHV-JHM), have a notable difference at this site. MHV-A59 has an RR-S-H-R-S sequence and is less efficiently cleaved than MHV-JHM, which has an R-R-A-S-S-R sequence (18). P4 is generally considered to be critical for furin cleavage, but we found limited variation in this residue position for the FIPVs tested and found mutation to the polar basic residue (K) or polar uncharged residue (S) in $<5 \%$ of viruses. The peptide data indicates that, although introduction of a serine at $\mathrm{P} 4$ completely abrogates cleavage, the $\mathrm{P} 4$ $\mathrm{R} \rightarrow \mathrm{K}$ substitution has minimal effect. The FIPV P3 position showed small variation compared with FECV after the introduction of a polar uncharged residue (T) in 1 sample. For the P5 position, the only change was a slightly higher frequency of the lysine residue in samples from cats with FIPV. Peptide cleavage data indicated that the common S-A substitution found for FECV and FIPV P3 positions has only slightly increasing effect on proteolysis by furin. Furthermore, the P5 $\mathrm{R} \rightarrow \mathrm{K}$ substitution has an enhancing effect in the peptide cleavage assay. At $\mathrm{P}^{\prime}$, the conserved polar uncharged residue (S) was retained in the majority of FIPV samples, however, the introduction of an aliphatic amino acid (L) was found. It is notable that furin cleavage has been suggested to be incompatible with a hydrophobic aliphatic side chain, with a strong preference for serine in 


\begin{tabular}{|c|c|c|c|}
\hline Peptide name & Sequence & $\begin{array}{l}\text { \%THTRRSRRSAPA } \\
\text { Sequence Vmax }\end{array}$ & $\begin{array}{l}\text { ProP } 1.0 \\
\text { Prediction score }\end{array}$ \\
\hline Canonical & THTRRSRRSAPA & $100 \%$ & 0.786 \\
\hline P1'SL & THTRRSRRLAPA & $8 \%$ & 0.603 \\
\hline P1 R-G & THTRRSRGSAPA & $-2 \%$ & 0.000 \\
\hline P1 R-M & THTRRSRMSAPA & $-5 \%$ & 0.000 \\
\hline P1 R-T & THTRRSRISAPA & $-5 \%$ & 0.000 \\
\hline P2 R-H & THTRRS吕SAPA & $0 \%$ & 0.632 \\
\hline P2 R-L & THTRRSLRSAPA & $52 \%$ & 0.590 \\
\hline P2 R-P & THTRRSERSAPA & $129 \%$ & 0.662 \\
\hline P2 R-S & THTRRS $\underline{\text { SRSAPA }}$ & $19 \%$ & 0.618 \\
\hline P3 S-A & THTRRARRSAPA & $124 \%$ & 0.762 \\
\hline P4 R-K & THTRKS & $83 \%$ & 0.464 \\
\hline P4 R-S & THTRS̄SRRSAPA & $-3 \%$ & 0.376 \\
\hline P5 R-K & THTKR RRRSAPA & $149 \%$ & 0.749 \\
\hline P6 T-F & THERRSRRSAPA & $162 \%$ & 0.776 \\
\hline P7 H-Q & TQTTRRSRRSAPA & $186 \%$ & 0.787 \\
\hline P7 H-Q P5 R-K & TQ̄TKKRSRSAPA & $232 \%$ & 0.748 \\
\hline
\end{tabular}

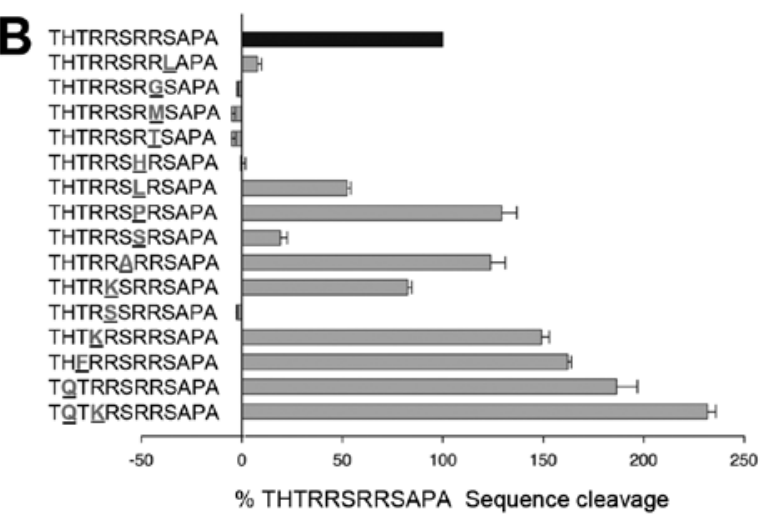

Figure 4. Furin cleavage assays of fluorogenic peptides. A) Synthetic fluorogenic peptides were generated with sequences matching consensus feline enteric coronavirus and a panel of modified sequences with substitutions (underlined) found by feline infectious peritonitis virus sequencing. Peptides $(50 \mu \mathrm{mol} / \mathrm{L})$ were subjected to cleavage by recombinant human furin $(1 \mathrm{U} / 100 \mu \mathrm{L})$, at $\mathrm{pH} 7.5,30^{\circ} \mathrm{C}$, and the release of fluorescence over time was measured by a spectrofluorometer enabling calculation of the Vmax of each reaction. Peptide cleavage scores generated by the ProP 1.0 server (www.cbs.dtu.dk/services/ProP/) are also displayed. B) For each modified peptide (substitutions underlined), the percentage of cleavage rate compared with the canonical sequence was calculated and displayed. Cleavage assays were performed in $>3$ independent experiments. Error bars indicate SD for each measurement.

the P1' position $(27,29)$. In the D04-397-2 sample containing the $\mathrm{P} 1^{\prime} \mathrm{L}$, the basic residues within the $\mathrm{S} 1 / \mathrm{S} 2$ site remain identical to the ones found in FECV sequence; we suggest that disruption of furin cleavage is mediated by a mutation in $\mathrm{P} 1^{\prime}$, rather than the more typical $\mathrm{P} 1, \mathrm{P} 2$ and/or P4 mutation. This hypothesis is supported by the peptide cleavage assay, where the P1'S-L peptide is unable to be cleaved by furin.

Overall, in terms of FIP-positive animals, we found that 10 of 11 cats harbored viruses with mutations in the furin motif R-R-S/A-R-R-S found in FECV of asymptomatic cats. For most FIP-positive cats, we sequenced viral RNA collected from different tissues (online Technical Appendix Table 1). Our data provides strong support for the internal mutation hypothesis, as the mutations are unique to individual cats.

Of note, not all tissues from the same animal carry the same mutation. In some instances, mixed populations of viruses exist within the same animal. The majority of viruses sequenced had 1 mutation, although 5 (D06-244-1, D06244-2, 08-153990-2, N07-95-1, and D04-93-2) had 2 mutations. However, there are 2 apparent exceptions of cats harboring viruses that do not have clearly defined mutations in the furin cleavage site: samples from cat $151643(1-3)$ and samples from cat N05-110 $(1,2)$. We consider that the presence of a P6 furin cleavage in samples of cat 151643 is consistent with our hypothesis of a switch in the activating protease for the virus, because this is not typical of naturally occurring furin cleavage sites. Samples 1 and 2 from cat N05-110 harbor virus with an atypical lysine residue at P5. While unusual for FECVs, a P5 lysine residue does appear to be compatible with furin cleavage, so it remains to be determined how noteworthy a P5 lysine residue versus a P5 arginine residue is in the context of a protease switch for FIPV, or whether other mutations correlated with FIPV in the case of this cat.

As part of our study, we analyzed field samples from cats harboring $\mathrm{FCoV}$ at different times. In cat 234, the virus underwent a transition from FECV to FIPV, and had a functionally relevant mutation in the S1/S2 motif (P2 R-L). Cat 304, living in the same house as cat 234, remained asymptomatic. Cat 304 harbored a mutated virus, but the mutation was in a functionally irrelevant position (P3 S-A). Identification of cats with FECV in which FIP subsequently develops is challenging, and while we present a single example, we consider these data to be strong evidence that mutations at the $\mathrm{S} 1 / \mathrm{S} 2$ site are linked to a change in the pathogenic properties of the virus, and likely to be essential for the acquisition of macrophage tropism seen in FIP.

The S1/S2 cleavage site and surrounding residues of serotype 1 FIPV S sequences were found to be systematically modified by mutations. Chang et al. recently published an extensive comparative analysis of FIP mutations at the nucleotide level by performing whole-genome sequencing of FECVs and FIPVs; the authors found a site within S (nucleotide position 23531), but outside of S1/ $\mathrm{S} 2$, to be the most frequently mutated in FIPV (15). We have undertaken an analysis of the $\mathrm{S} 1 / \mathrm{S} 2$ sites sequenced by Chang et al. and find that our hypothesis that mutation within the S1/S2 furin motif correlates with FIP in $\approx 64 \%$ of their samples. There are 3 differences in methodology that may explain this lack of agreement: first, we employed immunohistochemistry to confirm the diagnosis of FIP, while Chang et al. reported using postmortem examination; second, all FIP samples in this study originate from tissue, 
Table 1. Status of cats sampled for feline coronavirus and mutations in spike protein cleavage site ${ }^{*}$

\begin{tabular}{lccc}
\hline & $\begin{array}{c}\text { FECV- } \\
\text { infected cats }\end{array}$ & $\begin{array}{c}\text { FIPV- } \\
\text { infected cats }\end{array}$ & Total \\
\hline $\begin{array}{l}\text { Cats harboring viruses with } \\
\geq 1 \text { mutated S1/S2 site }\end{array}$ & 2 & 10 & 12 \\
$\begin{array}{l}\text { Cats harboring viruses with } \\
\text { an intact S1/S2 site }\end{array}$ & 28 & 1 & 29 \\
$\begin{array}{l}\text { Total } \\
\text { FECV, feline enteric coronavirus; FIPV, feline infectious peritonitis; S1, } \\
\text { receptor-binding domain of spike; S2, fusion domain of spike. }\end{array}$ \\
\hline
\end{tabular}

while Chang et al. included both tissue and ascites fluid; and finally, we report multiple sequences for FIP-affected cats, while Chang et al. reported a single sequence. Sequence data from samples D04-397-1 and D04-397-2 provide evidence that both FECV and FIPV populations can be identified within an affected animal. Sequence information from a single sample may not be adequate for the detection of mutated virus.

Most mutations negatively affect furin processing, but some enhance it. Given that the majority of the FIPV S proteins still harbor basic residues at the $\mathrm{S} 1 / \mathrm{S} 2$ boundary, it could be reasoned that the mutated site becomes more open and can be cleaved by a range of other proteases. The switch in proteolytic requirements of $\mathrm{S}$ that we propose may offer an explanation for the crucial tropism transition during FIP. A possible consequence of the mutations is cleavability by monocytic/macrophage-specific proteases. These could be pro-protein convertases, cathepsins, or other macrophagespecific proteases. In particular, cathepsin B, matrix metalloproteases, and furin-related PCSK1 are likely to be expressed on the surface of macrophages and recognize the hallmark residues remaining or acquired in FIPV S1/S2 cleavage site (30). Matrix metalloprotease 9 is of particular interest because it was demonstrated to be upregulated in activated monocytes and macrophages during FIP (31). A shift in the entry pathway to enable virus entry at the cell surface instead of the endosome may simultaneously explain the ability of FIPV to infect macrophages and the macrophage resistance of FECV. It is also possible that the mutations in the S1/S2 region affect the heparin sulfate binding site in this region (19). However, heparin sulfate binding is a cell culture adaptation of the virus, and as so, its relevance to the clinical situation would appear to be unlikely.

A contrasting view to the internal mutation hypothesis to explain the genesis of FIP outbreaks is that there

Table 2. Sequence of FCoV spike at S1/S2 junction in cats sampled for feline coronavirus*

\begin{tabular}{|c|c|c|}
\hline Time & Cat 234 & Cat 304 \\
\hline$t=1$ & NHTHTRRSRR $\downarrow S A P V A V$ & NHTHTRRSRR $\downarrow S A P V A V$ \\
\hline$t=2$ & NHTHTRRSLR $\downarrow S A P V A V$ & NHTHTRRARR $\downarrow S A P V A V$ \\
\hline
\end{tabular}

is a circulating FCOV other than FECV that is specific for FIP (22). For a complex disease process such as FIP, we and others consider it likely that there may be circulating FECVs that are closer to making the critical mutations necessary for FIP, possibly explaining paradoxical FIP outbreaks (32). Based on the data we present here, we conclude that mutation of the S1/S2 locus and modulation of a furin recognition site normally present in the $\mathrm{S}$ gene of FECVs is a critical contributing factor for development of FIP. Further studies could serve to analyze how S1/S2 mutations fit with the other mutations posited to account for FIP development.

\section{Acknowledgments}

The authors thank Meredith Brown, Stephen O'Brien, Sean McDonough, and Edward Dubovi for providing some of the clinical samples used in this study and Nadia Chapman and Wendy Wingate for technical assistance. We thank Nabil Seidah for helpful advice and comments and for providing PSCK-9 reagents and Sara Sawyer for helpful comments. We would also like to thank Jing Yang for assistance with statistical analysis.

This research was supported by grants from the Cornell Feline Health Center, the Winn Feline Health Foundation, and the Morris Animal Foundation. A.D.R. was supported by grant T32AI007618 (Training in Molecular Virology and Pathogenesis) from the National Institutes of Health. The sponsors had no influence in the study design, the collection, analysis and interpretation of data, the writing of the manuscript, or in the decision to submit the manuscript for publication. All work was approved by the Institutional Animal Use and Care Committee at Cornell University (Ithaca, NY).

Ms Licitra is a dual-degree $(\mathrm{DVM} / \mathrm{PhD})$ graduate student in the Whittaker Laboratory, in the Department of Microbiology and Immunology, College of Veterinary Medicine, Cornell University, Ithaca, NY, USA. Her research interests include zoonotic and vector-borne diseases and microbial pathogenesis.

\section{References}

1. Haijema BJ, Rottier PJ, de Groot RJ. Feline coronaviruses: a tale of two-faced types. In: Thiel V, editor. Coronaviruses: molecular and cellular biology. Norfolk (UK): Caister Academic Press; 2007. p. 183-203.

2. King AMQ, Lefkowitz E, Adams MJ, Carstens EB. Virus taxonomy: IXth Report of the International Committee on Taxonomy of Viruses. London:,Elsevier; 2011.

3. Hohdatsu T, Okada S, Ishizuka Y, Yamada H, Koyama H. The prevalence of types I and II feline coronavirus infections in cats. J Vet Med Sci. 1992;54:557-62. http://dx.doi.org/10.1292/jvms.54.557

4. Benetka V, Kubber-Heiss A, Kolodziejek J, Nowotny N, Hofmann-Parisot M, Mostl K. Prevalence of feline coronavirus types I and II in cats with histopathologically verified feline infectious peritonitis. Vet Microbiol. 2004;99:31-42. http://dx.doi.org/10.1016/ j.vetmic.2003.07.010 
5. Shiba N, Maeda K, Kato H, Mochizuki M, Iwata H. Differentiation of feline coronavirus type I and II infections by virus neutralization test. Vet Microbiol. 2007;124:348-52. http://dx.doi.org/10.1016/ j.vetmic.2007.04.031

6. Herrewegh AA, Mahler M, Hedrich HJ, Haagmans BL, Egberink $\mathrm{HF}$, Horzinek MC, et al. Persistence and evolution of feline coronavirus in a closed cat-breeding colony. Virology. 1997;234:349-63. http://dx.doi.org/10.1006/viro.1997.8663

7. Pedersen NC, Allen CE, Lyons LA. Pathogenesis of feline enteric coronavirus infection. J Feline Med Surg. 2008;10:529-41. http://dx.doi.org/10.1016/j.jfms.2008.02.006

8. Pedersen NC, Boyle JF, Floyd K, Fudge A, Barker J. An enteric coronavirus infection of cats and its relationship to feline infectious peritonitis. Am J Vet Res. 1981;42:368-77.

9. Herrewegh AA, Vennema H, Horzinek MC, Rottier PJ, de Groot RJ. The molecular genetics of feline coronaviruses: comparative sequence analysis of the ORF7a/7b transcription unit of different biotypes. Virology. 1995;212:622-31. http://dx.doi.org/10.1006/ viro. 1995.1520

10. Vennema H, Poland A, Foley J, Pedersen NC. Feline infectious peritonitis viruses arise by mutation from endemic feline enteric coronaviruses. Virology. 1998;243:150-7. http://dx.doi.org/10.1006/ viro.1998.9045

11. Poland AM, Vennema H, Foley JE, Pedersen NC. Two related strains of feline infectious peritonitis virus isolated from immunocompromised cats infected with a feline enteric coronavirus. J Clin Microbiol. 1996;34:3180-4.

12. Pedersen NC. A review of feline infectious peritonitis virus infection: 1963-2008. J Feline Med Surg. 2009;11:225-58. http://dx.doi.org/10.1016/j.jfms.2008.09.008

13. Salemi M, Fitch WM, Ciccozzi M, Ruiz-Alvarez MJ, Rezza G, Lewis MJ. Severe acute respiratory syndrome coronavirus sequence characteristics and evolutionary rate estimate from maximum likelihood analysis. J Virol. 2004;78:1602-3. http://dx.doi. org/10.1128/JVI.78.3.1602-1603.2004

14. Vijgen L, Keyaerts E, Moes E, Thoelen I, Wollants E, Lemey P, et al. Complete genomic sequence of human coronavirus OC43: molecular clock analysis suggests a relatively recent zoonotic coronavirus transmission event. J Virol. 2005;79:1595-604. http://dx.doi.org/10.1128/JVI.79.3.1595-1604.2005

15. Chang HW, Egberink HF, Halpin R, Spiro DJ, Rottier PJ. Spike protein fusion peptide and feline coronavirus virulence. Emerg Infect Dis. 2012;18:1089-95. http://dx.doi.org/10.3201/eid1807.120143

16. Rottier PJ, Nakamura K, Schellen P, Volders H, Haijema BJ. Acquisition of macrophage tropism during the pathogenesis of feline infectious peritonitis is determined by mutations in the feline coronavirus spike protein. J Virol. 2005;79:14122-30. http://dx.doi. org/10.1128/JVI.79.22.14122-14130.2005

17. Klenk H-D, Garten W. Activation cleavage of viral spike proteins by host proteases. In: Wimmer E, editor. Cellular receptors for animal viruses. Cold Spring Harbor (NY): Cold Spring Harbor Press; 1994. p. 241-80.

18. Bosch BJ, Rottier PJ. Nidovirus entry into cells. In: Perlman S, Gallagher T, Snijder EJ, editors. Nidoviruses. Washington (DC): ASM Press; 2008. p. 157-78.

19. de Haan CAM, Haijema BJ, Schellen P, Schreur PW, te Lintelo E, Vennema $\mathrm{H}$, et al. Cleavage of group 1 coronavirus spike proteins: how furin cleavagei traded off against heparan sulfate binding upon cell culture adaptation. J Virol. 2008;82:6078-83. http://dx.doi. org/10.1128/JVI.00074-08

20. Seidah NG, Prat A. The biology and therapeutic targeting of the proprotein convertases. Nat Rev Drug Discov. 2012;11:367-83. http://dx.doi.org/10.1038/nrd3699

21. Thomas G. Furin at the cutting edge: from protein traffic to embryo genesis and disease. Nat Rev Mol Cell Biol. 2002;3:753-66. http://dx.doi.org/10.1038/nrm934
22. Brown MA, Troyer JL, Pecon-Slattery J, Roelke ME, O'Brien SJ. Genetics and pathogenesis of feline infectious peritonitis virus. Emerg Infect Dis. 2009;15:1445-52. http://dx.doi.org/10.3201/eid1509.081573

23. Pedersen NC, Liu H, Dodd K, Pesavento P. Significance of coronavirus mutants in feces and diseased tissues of cats suffering from feline infectious peritonitis. Viruses. 2009;1:166-84. http://dx.doi.org/10.3390/v1020166

24. Chang HW, Egberink HF, Rottier PJ. Sequence analysis of feline coronaviruses and the circulating virulent/avirulent theory. Emerg Infect Dis. 2011;17:744-6. http://dx.doi.org/10.3201/eid1704.102027

25. Herrewegh AA, de Groot RJ, Cepica A, Egberink HF, Horzinek MC, Rottier PJ. Detection of feline coronavirus RNA in feces, tissues, and body fluids of naturally infected cats by reverse transcriptase PCR. J Clin Microbiol. 1995;33:684-9.

26. Rockwell NC, Krysan DJ, Komiyama T, Fuller RS. Precursor processing by kex2/furin proteases. Chem Rev. 2002;102:4525-48. http://dx.doi.org/10.1021/cr010168i

27. Nakayama K. Furin: a mammalian subtilisin/Kex2p-like endoprotease involved in processing of a wide variety of precursor proteins. Biochem J. 1997;327:625-35.

28. Henrich S, Cameron A, Bourenkov GP, Kiefersauer R, Huber R, Lindberg I, et al. The crystal structure of the proprotein processing proteinase furin explains its stringent specificity. Nat Struct Biol. 2003;10:520-6. http://dx.doi.org/10.1038/nsb941

29. Izidoro MA, Gouvea IE, Santos JA, Assis DM, Oliveira V, Judice WA, et al. A study of human furin specificity using synthetic peptides derived from natural substrates, and effects of potassium ions. Arch Biochem Biophys. 2009;487:105-14. http://dx.doi.org/10.1016/j. abb.2009.05.013

30. Refaie S, Gagnon S, Gagnon H, Desjardins R, D'Anjou F, D'Orléans-Juste $\mathrm{P}$, et al. Disruption of proprotein convertase $1 / 3$ $(\mathrm{PC} 1 / 3)$ expression in mice causes innate immune defects and uncontrolled cytokine secretion. J Biol Chem. 2012;287:14703-17. http://dx.doi.org/10.1074/jbc.M111.323220

31. Kipar A, May H, Menger S, Weber M, Leukert W, Reinacher M. Morphologic features and development of granulomatous vasculitis in feline infectious peritonitis. Vet Pathol. 2005;42:321-30. http://dx.doi.org/10.1354/vp.42-3-321

32. O'Brien SJ, Troyer JL, Brown MA, Johnson WE, Antunes A, Roelke ME, et al. Emerging viruses in the felidae: shifting paradigms. Viruses. 2012;4:236-57. http://dx.doi.org/10.3390/v4020236

Address for correspondence: Gary Whittaker, Department of Microbiology and Immunology, Cornell University, Ithaca, NY 14853, USA; email: grw7@cornell.edu

\section{The Public Health Image Library (PHIL)}

The Public Health Image Library (PHIL), Centers for Disease Control and Prevention, contains thousands of public health-related images, including high-resolution (print quality) photographs, illustrations, and videos.

PHIL collections illustrate current events and articles, supply visual content for health promotion brochures, document the effects of disease, and enhance instructional media.

PHIL Images, accessible to PC and Macintosh users, are in the public domain and available without charge.

Visit PHIL at http://phil.cdc.gov/phil. 